\title{
Wrap-up Summary and Research Priorities Identified at the Workshop
}

\author{
Mark Saunders
}

\author{
IYS Director for the North Pacific
}

The NPAFC-IYS workshop in Khabarovsk was the first of a series of four IYS workshops that will be held in conjunction with NPAFC annual meetings through 2021. One of the reasons for hosting IYS workshops at successive annual meetings is to provide an opportunity to build awareness of the IYS in each NPAFC country and to encourage greater participation by researchers from host countries. This was certainly the case as we had a strong contingent of Russian scientists.

I was both excited and nervous as this workshop represented the beginning of a new process that we expect to be transformative for our approach to research. NPAFC research is guided by a five-year Science Plan that includes goals and research themes. In the past, each country reported annually on activities related to each theme and in the final year of the plan the Science Sub-Committee summarized progress. This retrospective approach was quite challenging. The current plan runs from 2016-2020 and was designed to complement the International Year of the Salmon (IYS) and its five research themes/outcomes. It was decided that annual IYS workshops would provide a good opportunity to document progress on each of the themes and facilitate continuous learning over the four years of the initiative.

Continuous learning is an important element of the IYS, where over its lifetime we want to use a combination of research projects and Workshops/Symposia to achieve IYS outcomes that will collectively establish the conditions for the resilience of salmon and people. This first workshop focussed on the outcome "Status of Salmon", framed for the North Pacific as "Status of Pacific Salmon and Steelhead Trout". It will inform subsequent work over the next year to plan and seek funding for projects.

\begin{tabular}{|c|c|}
\hline \multicolumn{2}{|r|}{ IYS OUTCOMES } \\
\hline Status of salmon & The present status of salmon and their environments is understood. \\
\hline $\begin{array}{l}\text { Salmon in a changing } \\
\text { salmosphere }\end{array}$ & $\begin{array}{l}\text { The effects of natural environmental variability and human factors affecting salmon } \\
\text { distribution and abundance are understood and quantified. }\end{array}$ \\
\hline New frontiers & $\begin{array}{l}\text { New technologies and analytical methods are advanced and applied to salmon research. } \\
\text { Research is carried out to fill gaps in poorly studied regions of the salmosphere. }\end{array}$ \\
\hline Human dimensions & $\begin{array}{l}\text { Communities, Indigenous Peoples, youth, harvesters, scientists and resource managers } \\
\text { across the Northern Hemisphere share knowledge and collaborate in the development of } \\
\text { new tools and approaches to restoring, managing and sustaining salmon. }\end{array}$ \\
\hline Information systems & $\begin{array}{l}\text { Freely available information systems contain historic and current data about salmon and } \\
\text { their environment. }\end{array}$ \\
\hline $\begin{array}{l}\text { Salmon outreach and } \\
\text { communication }\end{array}$ & $\begin{array}{l}\text { People understand the value of healthy salmon populations and engage to ensure } \\
\text { salmon and their varied habitats are conserved and restored against the backdrop of } \\
\text { increasing environmental change. }\end{array}$ \\
\hline
\end{tabular}

I had the pleasure of chairing a panel discussion at the end of the two days where I asked: What did we learn with respect to our research outcomes? What gaps and resulting priorities did we identify? Often when we attempt to hold plenary sessions of this type, those most fluent in English often dominate. I was very pleased with the lively discussion and scientific debate that engaged people from every country, despite the fact that it was at the end of a very long week for all of us.

Below I provide brief summary statements of what we learned and gaps identified. In October 2018 Theme Counsel Groups will be formed to engage experts from each country in planning for the IYS research themes. I provide some recommended priorities for the Theme Counsel Groups to consider and potentially address through further workshops/symposia or research projects.

As mentioned earlier, the "Status of Salmon" topic was a focus for the workshop. We learned that: 
- Status appears to be documented to a degree in all regions, with at least catch statistics available to infer status;

- Stocks are generally doing better in the north;

- Some common trends in many stocks include declining size at age, and shifts to younger age classes;

- Chinook exhibit a general trend of poor status;

- $\quad$ North American and Russian chum and pink stocks are generally doing well or very well;

- Japanese and Korean chum have exhibited declines in recent years; and

- There is a gap in information on steelhead trout.

Priority: It was agreed that the status of salmon in the North Pacific is not well understood and there is a need for collated and standardized data on the status of salmon to be made available. Additionally, there is a need for an atlas and/or other tools to tell the "salmon story" in simple and compelling ways to the informed public and the general public.

Recommendation: Theme Counsel Group for the Status of Salmon and Salmon in a Changing Salmosphere consider convening a workshop on the collation, standardization and communication of data and information on the Status of Salmon.

Gap: Lack of information on the status of Steelhead Trout.

Recommendation: Theme Counsel Group for the Status of Salmon and Salmon in a Changing Salmosphere consider steps required to address the gap.

The "Pacific Salmon and Steelhead Trout in a Changing North Pacific Ocean" topic was thought-provoking, which is not surprising given the title of the workshop. We learned:

- There are a range of approaches being used in the western and eastern North Pacific to link climate and salmon production, and there is a need to synthesize these methods;

- Sea Surface Temperature is the common currency to examine local and regional linkages to a changing environment;

- There is a need to investigate the mechanisms behind linkages to climate indices;

- There is a need to resolve the "critical period hypotheses";

- Impact of competition is a key topic, especially if carrying capacity is reached;

- Year class strength is set at different times depending on the ecosystem;

- That anomalous 2015-2017 conditions are breaking down long standing relationships with ocean and climate indices;

- Continued warming of the North Pacific Ocean will likely affect migration routes and predicted available area for distribution in the future but to what extent?;

- There is improved understanding of chum migration in Japan and Korea;

- Pink/chum/sockeye are migrating into the Arctic and have potential as a sentinel species. An interesting human dimension project is underway to explore the impact of these changes on northern Indigenous Peoples. There is genetic work underway to determine where the sockeye and pink are coming from;

- There is an increasing focus on linking behaviour of individual fish to physiological triggers that are driven by changes in the environment;

- Extreme freshwater events are having significant impacts on fish populations; and

- Algal blooms are affecting salmon populations and we could learn from documenting events across the basin. It is unknown what specifically triggers blooms.

Recommendation: The Theme Counsel Group for Status of Salmon and Salmon in a Changing Salmosphere should consider the following:

- Review Santa Barbara Workshop recommendations for linking climate and salmon —including mechanisms behind shifts in distribution, migration and productivity;

- Develop an approach to address "critical period hypothesis" — linkage to High Seas Ecosystem Signature project;

- Develop an approach to assess carrying capacity of the North Pacific Ocean-linkage to High Seas Ecosystem Signature project;

- Develop an approach to advancing modelling of the behaviour of individual fish; 
- Develop an approach to monitoring and understanding the impact of algal blooms and extreme freshwater events; and

- Apply the "Likely Suspects Framework" in the Pacific basin to effectively integrate understanding of the linkages and bottlenecks affecting survival across life history stages.

The third topic covered the remaining three themes New technologies, Management, and Information systems. We learned:

- Forty percent of salmon biomass in the North Pacific are hatchery fish;

- Adaptive hatchery management will be needed in the face of uncertain environments;

- Japan is developing new strategies varying holding methods and time of release;

- Survey indices can effectively predict returns when they survey a life history stage where cohort strength is set and subsequent ecosystems are stable;

- There is a need to incorporate environmental conditions into forecasts;

- There is a need for independent research for steelhead assessments; and

- There is a need to engage fisheries and resource managers in the IYS.

Recommendation: The Theme Counsel Group for New Frontiers and Information Systems should consider the following:

- Convene a workshop on adaptive management in hatcheries in an uncertain environment. Recommendation: The Theme Counsel Group for the Human Dimensions should consider the following:

- Convene a Salmon Resource management advisory group to engage managers in the development of research that is relevant and helpful to management.

There were several suggestions for improvement of the workshop that organizing committees for subsequent IYS Workshops should consider:

- $\quad$ use web-technology to make sure the broader community of scientists across the hemisphere have an opportunity to learn from these meetings. We publish abstracts from workshops and proceedings from symposia but there are additional ways to engage a broader audience. As a matter of course, we could be webcasting and recording talks so that people can watch them later. Facebook has the capacity to broadcast live and engage audiences if desired. Language is a barrier, but countries could add a translated soundtrack later;

- Each talk should start with a Google Map that zooms into the area of interest for the talk;

- The task of providing a more detailed synthesis of what is learned from each session could be improved by:

- asking members of the Theme Counsel Groups to draft the synthesis for their related theme/outcome

- ask presenters to assess in advance the contribution of their work to the research theme/outcome. 